\title{
Construction of water supply and drainage engineering
}

\author{
Haiying Zhang \\ School of Chemical and Environmental Engineering, Shanghai Institute of Technology, Shanghai, China
}

\begin{abstract}
Construction of water supply and drainage engineering is one of the main special courses offered to students whose major is Water Supply and Drainage. Through learning of this course, the students should understand earth and rock works, water drainage in the process of construction, pipe slotting construction, non- pipe slotting construction, underwater construction, energy-saving and noise reduction in the design of water supply and drainage system, mechanical equipment installation, water structure, and maintenance and maintenance. Urban supply system and drainage system are major strong guarantee of development of cities and one of an important infrastructure projects. Therefore, it is required to culture graduate in the field of water supply and drainage engineering. The paper offers a construction plan for the course in the following aspects: revision of teaching content, improvement of teaching method, arrangement of test database and exercise database and ways to increasing teaching effect of this course, and result of construction.
\end{abstract}

\section{Introduction}

In recent years, the process of water supply and drainage accelerates rapidly with the rapid development of national economy and city of our country, but there are many problems. The pipeline installation does not meet specifications, quality standards, waste etc.. In order to promote the development of water quality, energy saving and water quality improvement, it is necessary to pay attention to these aspects in the process of college education [1].

Water supply systems get water from a variety of locations after appropriate treatment, including groundwater (aquifers), surface water (lakes and rivers), and the sea through desalination. The water treatment steps include, in most cases, purification, disinfection through chlorination and sometimes fluoridation[2,3]. Treated water then either flows by gravity or is pumped to reservoirs, which can be elevated such as water towers or on the ground (for indicators related to the efficiency of drinking water distribution see non-revenue water). Once water is used, wastewater is typically discharged in a sewer system and treated in a sewage treatment plant before being discharged into a river, lake or the sea or reused for landscaping, irrigation or industrial use (see also sanitation)[4].

The present situation of water supply and drainage engineering in China is quite important. In our country the city water supply, insufficient water supply capacity in some city, residential and public buildings in city development lags behind the development of water. The decline in pipeline aging and bearing capacity can not meet the water requirements, so that our two pressurized equipment widely used, boosting facilities as a proportion of building water supply device in the fastest developing [5,6]. Therefore, water supply and drainage technologies are quite important, which need special professionals to carry out the construction process. This is one of the aims of this course, which requires construction to cultivate graduates special in up-to-date water supply and drainage construction methods.

This course targets undergraduate students, whose major is Water Supply and Drainage. The teaching mode is class teaching and discussion. Through the course the student can master the basic theory and major technologies used in aspects of water saving, collecting and processing natural water resource, water-saving device and rainwater utilization. It explores the application of new technology in water supply and drainage engineering, which not only optimizes water supply and drainage system, but also improves the water source using efficiency. Experimental class is also offered to improve the ability of students to apply knowledge to practical problems. In addition, we also introduce the development direction and achievement of this subject during our teaching.

This paper first analyzes the current conditions of this course and reasons for construction of this course. In addition, a developing plan for the course construction was offered in the following aspects: adjustment of the course content, reorganization of the textbook, improvement of teaching methods and class modes, test database and exercise database and ways to increase teaching quality of this course.

\section{Current conditions and necessity of developing this course}

\subsection{Current conditions}

*Corresponding author: a Haiying Zhang: juli506@126.org 
This course of Construction of Water Supply and Drainage Engineering is a major and special course of Water Supply and Drainage Engineering. It involves four parts, involving basic knowledge, supply and drainage pipes, water structures, and maintenance and maintenance. Through learning of this course, the students should understand earth and rock works, water drainage in the process of construction, pipe slotting construction, non- pipe slotting construction, underwater construction, energy-saving and noise reduction in the design of water supply and drainage system, mechanical equipment installation, water structure, and maintenance and maintenance.

\subsection{The requirement of development of water supply and drainage in China}

China is confronted with fast development of economy and urbanization process. Consequently, water requirement increased quickly, which is a big challenge of China [5,6]. Water supply and drainage is an important constituent of urban infrastructure projects. While some problems exist, for example, shortage of water supply, poor drainage system, and waste of water resources. These problems influence life of people.

Urban supply system and drainage system are major strong guarantee of development of cities and one of an important infrastructure projects. Therefore, it is required to culture graduate in the field of water supply and drainage engineering.

\section{Construction of the course}

\subsection{Adjustment of the content of Construction of Water Supply and Drainage}

Prior to construction, this course involves four parts. Part 1 is pipe slotting construction, including preparation before construction, trench excavation, base processing for pipes, below and installation of pipes, final check after construction. Part 2 is non- pipe slotting construction, including pipe jacking construction, directional drilling construction. Part 3 is construction of subsidiary water structures, including construction of valve well, rainwater outlet construction, check well construction, and septic tank construction. Part 4 is water treatment structures construction, including clean water structure, waste water treatment structure, function test of the structures.

Considering fast development of water supply and drainage in China, the content of the theoretical class was revised. After construction, the course involves 12 chapters. Chapter one is earth and rock works, including soil characteristics, site levelling, earth construction, shoring of trench and foundation pit, earthwork backfilling. Chapter two is water drainage in the process of construction and base preparation, including open drainage, manual lowering of groundwater level, base preparation. Chapter three is pipe slotting construction, including measurement and lining up, down pipe and stabilizing pipe, water-supply pipe construction, drainage pipe construction, $\mathrm{PE}$ and $\mathrm{PVC}$ pipe construction, final check. Chapter four is non- pipe slotting construction, including pipe jacking construction, directional drilling construction. Chapter five is underwater pipe construction, including underwater excavation of ditches, underwater pipe connection, underwater pipe spreading. Chapter six is installation of pipe in buildings and installation of sanitary apparatus, including preparation, steel pipe machining and connection, non-steel pipe connection, pipe installation and installation of sanitary apparatus. Chapter seven is mechanical equipment installation, including water pump installation, air-blower installation. Chapter eight is water structure construction, including check well construction, reinforced concrete structure construction, well-sinking engineering construction, pipe well construction. Chapter nine is antisepsis and heat preservation, including surface treatment of pipes, antisepsis of pipes and heat preseration of pipe. Chapter ten is check and maintenance, including check and maintenance of water supply pipes, check and maintenance of drainage pipes.

\subsection{Reorganization of the textbook}

The course includes theoretical and experimental constituent, while no textbook meet this requirement. Textbook should be compiled. The textbook was reorganized based on Construction of Water Supply and Drainage Engineering written by Bian Xilong and published by China Architecture \& Building Press in 2011, Municipal Water Supply and Drainage Engineering by $\mathrm{Hu}$ Yun published by China Water\&Power Press in 2010, Water Supply and Drainage Engineering by Li Shihua published by China Architecture \& Building Press in 2007, Water Supply Engineering by Fan Jingchu published by China Architecture \& Building Press in 2010, Water Drainage Engineering by Xiu Hwei published by China Architecture \& Building Press in 2012.

\subsection{Teaching method}

This course of Construction of Water Supply and Drainage is taught using multimedia, including ppt (power point ) and CAI (Computing Aided Instruction). Multimedia refers to combination of a variety of mediatext, graphics, sound, animations, video and other visual information to make up an application system [5]. For example, Fig. 1 clearly describes principal elements that should be considered in planning, design, and operation of landfills. Through this picture, it is relatively easier for students to understand the knowledge. 


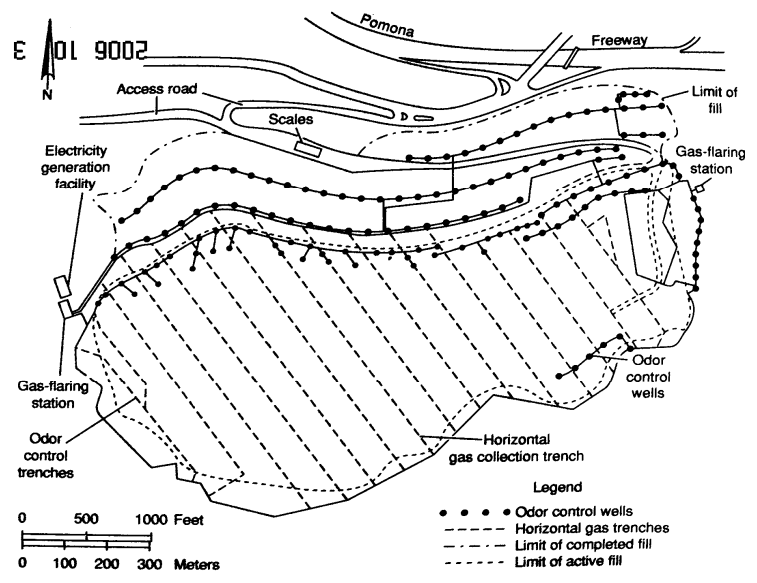

Fig. 1 Arrange of collection pipelines of leachate.

Leachate is highly contaminated liquid generated in the landfill, shown in Fig.2. Leachate composition depends largely on the age of landfill. Polluted water is discharged to rivers, lakes or ponds without proper treatment can cause serious pollution of water bodies. For example, polluted water bearing $\mathrm{Hg}$ caused Shuixu disease in Japanese. Leachate was generated during landfilling processes of wastes, which may pollute the environment and cause diseases if not collected and treated properly. For example, heavy metals and ammonia will pollute groundwater through percolation process.

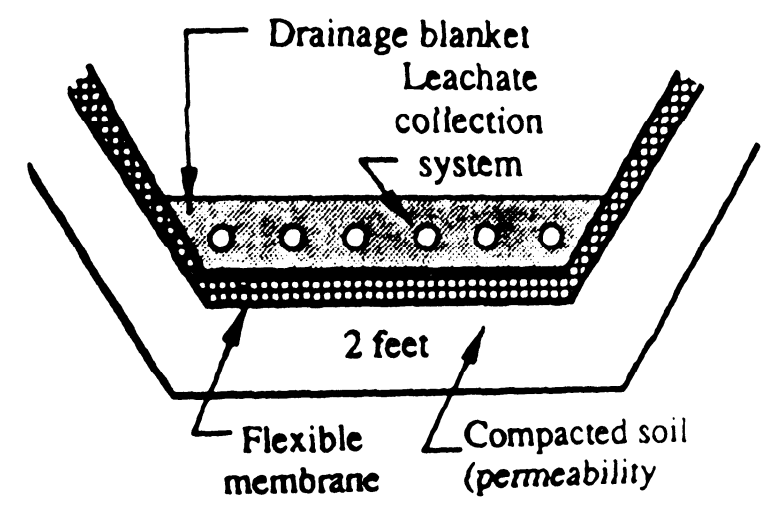

Fig. 2 Drainage pipes of leachate.

\subsection{Teaching types}

To improve teaching effect, students are encouraged to participate the process of course-teaching. In each classhouse, problems are provided for student discussion. In addition, the students are required to make a ppt on water supply and drainage for precipitation. Through discussion and precipitation, the students are closely involved in the class. Ppt and CAI software are used in teaching with ppt or CAI to explain the knowledge for an easier understanding.

Discussion and personal presentation are active learning and have better effects than passive learning. They are two important ways for students to participate in the teaching of this course. Discussion of relative topics, is regarded as a good way to enhance understanding of what is taught in the class.

\subsection{Test paper database and exercise database}

To check if the students grasp what is taught in the class, test paper database and exercise database are provided, which cover all contents of the course. 12 test papers were made, which would be chosen prior to examination. Exercise database was used in usual class test. Types of problems involve definition database, English to Chinese special word translation and Chinese to English translation database, explanation of diagrams, explanation of problems, computation.

Seven types of titles are involved in test papers. They are cloze, true or false, multiple choice, simple problem explanation, explanation of definition, discussion of problems, computation. They are made based on knowledge taught on class and video watched on class, and discussion topics.

\subsection{Analysis of construction result}

To analyze results of this course construction, questionnaires were conducted among students who attend this course. It was found that this course after construction is popular in students. The total number of students attending the course Construction of Water Supply and Drainage Engineering was 30 in 2015, 28 in 2016, 29 in 2017 and 28 in 2018. Analysis of the questionnaires on construction of this course was shown in Table 1. Over $89 \%$ of students was in support of this course construction and over $96 \%$ of them regard construction of this course is helpful for them. From 2015 to 2018, there is an increase of the number of students who are in support of construction of this course. Consequently, some students who are against of this course construction also think it is helpful for them.

Table 1. Analysis of questionnaires on construction of this course

\begin{tabular}{cccccc}
\hline Year & A & B & C & D & E \\
\hline 2015 & 27 & 10 & 2 & 27 & 2 \\
2016 & 29 & 7 & 2 & 27 & 1 \\
2017 & 33 & 7 & 1 & 31 & 0 \\
2018 & 33 & 6 & 0 & 29 & 0
\end{tabular}

A represents "Number of students in support of this course after construction".

B represents "Number of students against of this course construction".

C represents "Number of students that think both ok".

D represents "Number of students that regard construction is helpful".

E represents "Number of students that regard construction is not helpful".

The effect of construction was analyzed through questionnaires among students who take this course. This course was constructed in 2015. Sores in 2013 and 2014 are for students taking this course before construction, and those in 2015, 2016, 2017 and 2018 are for students attending this course after construction. Student ratios, for 2013 and 2014, with scores over 90 are between $7 \%$ and $10 \%$. Score less than 60 is between 
$16 \%$ and $21 \%$. While in 2015, 2016, 2017 and 2018, it is between $28 \%$ and $32 \%$ for student getting scores over 90 , and less than $3.5 \%$ for student with scores less than 60 . It is clear that scores after construction are relatively higher that those without construction.

Table 2. Analysis on results of construction

\begin{tabular}{cccccc}
\hline Year & A' & B' & C' & D' & E' \\
\hline 2013 & 2 & 9 & 8 & 4 & 6 \\
2014 & 3 & 8 & 9 & 5 & 5 \\
2015 & 9 & 9 & 6 & 5 & 1 \\
2016 & 8 & 14 & 5 & 1 & 0 \\
2017 & 9 & 13 & 6 & 1 & 0 \\
2018 & 9 & 13 & 4 & 1 & 1 \\
\hline
\end{tabular}

A' represents "number of students that get score between 90 and 100 in the final test".

B' represents "number of students that get score between 89 and 100 in the final test".

C' represents "number of students that get score between 79 and 70 in the final test".

D' represents "number of students that get score between 69 and 60 in the final test".

E' represents "number of students that get score less than 60 .

\section{Conclusions}

Considering rapid development of water supply and drainage in China, it is necessary for construction of this course to cultivate students who meet requirement of this field. Construction process involves revision of teaching content, improvement of teaching method, arrangement of test database and exercise database and ways to increasing teaching effect of this course, and result of construction.

After construction of this course, teaching effect is improved and scores after construction are relatively higher that those without construction. Through class teaching, discussion and personal presentation, students are closely involved in class study.

\section{References}

1. Yan Xushi, Liu Suiqing. Water Supply and Drainage Engineering. China Architecture \& Building Press, 2014.

2. Fan Jingchu.Water Supply Engineering. China Architecture \& Building Press, 2010.

3. Xiu Hwei. Water Drainage Engineering. China Architecture \& Building Press, 2012.

4. Bian Xilong. Construction of Water Supply and Drainage Engineering. China Architecture \& Building Press, 2011.

5. 5.J. Cazenave. Municipal Water Supply and Drainage Engineering. China Water\&Power Press, 2010.

6. Li Shihua. Water Supply and Drainage Engineering. China Architecture \& Building Press, 2007. 